Article

\title{
Systems Thinking Using SSM and TRIZ for Stakeholder Engagement in Infrastructure Megaprojects
}

\author{
Johan Ninan ${ }^{1, *(D)}$, Ibukun Phillips ${ }^{2}$, Shankar Sankaran ${ }^{3}(D)$ and Swaminathan Natarajan ${ }^{4}(D)$ \\ 1 Bartlett School of Construction and Project Management, University College London, London WC1E 6BT, UK \\ 2 School of Industrial Engineering, Purdue University, West Lafayette, IN 47907, USA; poluwase@purdue.edu \\ 3 School of Built Environment, University of Technology Sydney, Ultimo, NSW 2007, Australia; \\ Shankar.Sankaran@uts.edu.au \\ 4 Tata Consultancy Services (TCS), Chennai 600113, India; swami.n@tcs.com \\ * Correspondence: Johan.Ninan@gmail.com
}

Received: 29 June 2019; Accepted: 24 September 2019; Published: 26 September 2019

check for updates

\begin{abstract}
Infrastructure megaprojects straddle multiple stakeholder boundaries who have an interest in the project and are affected by the project. Multiple papers in the literature stress the need for holistic approaches to stakeholder engagement, as existing approaches only address the concerns of the noisy stakeholders. This research proposes an innovative approach in which Soft Systems Methodology (SSM) is used for understanding stakeholder concerns, complemented by the use of Theory of Inventive Problem Solving (TRIZ) for identifying innovative solutions to address conflicting stakeholder goals. The researchers simulated the stakeholder engagement of the Coimbatore metro rail project, in India, through a workshop setting in a classroom to check the feasibility of this approach for stakeholder engagement. The 15 participants of the workshop were divided into four groups representing different stakeholders of the project. Data was collected through participant observations by the authors and oral feedback from the participants. The results show that while SSM helped to capture the concerns and goals of each stakeholder, TRIZ helped to identify and dissolve conflicts among these goals through innovative solutions. The theoretical, practical and pedagogical contributions are highlighted.
\end{abstract}

Keywords: soft systems methodology; SSM; theory of inventive problem solving; TRIZ; stakeholder engagement; infrastructure projects

\section{Introduction}

Infrastructure projects are essential for the socio-economic development of an area in a country [1]. Due to this, many countries invest in infrastructure that turns out to be a megaproject due to its scale. This rise in megaprojects, i.e., projects that cost more than 1 billion USD, is supported by Flyvbjerg [2], who claims that the size of infrastructure projects has grown by $1.5 \%$ to $2.5 \%$ annually-equivalent to a doubling in project size two to three times per century. This implies that countries around the world are investing in megaprojects to meet their infrastructure needs and growth objectives. Multiple scholars argue that the difference between mega and non-megaprojects is not the money involved but the presence of some special characteristics [3,4] thereby classifying less expensive projects such as Built Operate Transfer (BOT), Public Private Partnerships (PPP), Private Finance Initiative (PFI), etc. as megaprojects. The distinguishing features of these megaprojects are their wider reach, longer duration, larger risks and uncertainties, widely disparate actors, broader areas of controversy, and excessive legal and regulatory issues [5]. These disparate actors, stakeholders, are defined as "any group or individual who can affect or is affected by the achievement of the organization's objectives" [6] (p. 46). 
Mitchell et al. propose a broader definition of stakeholders as virtually anyone who can have an impact on an organization's actions or experiences an impact as a result of them [7]. In their review of stakeholder literature in projects, Littau et al. [8] note that stakeholders can be classified in three ways: (a) those who have an interest in the project; (b) those who can affect the project; and (c) those who both have an interest in and can affect the project. Megaprojects due to their colossal nature and disparate interests affect more stakeholders than conventional projects, and have been classified as pluralistic settings - the presence of actors with conflicting objectives and diffused power [9].

Miller et al., in their study of more than 60 infrastructure megaprojects over a period of 20 years [10], highlight that these projects are rarely built with in-house resources but bring in multiple stakeholders in the form of sponsors, experts, contractors, government agencies, opposing stakeholders and other external players. Rather than the mere number of different organizational entities in the megaproject, it is the institutional differences such as divergent perceptions regarding the legitimate means and ends of the project that are a source of project complexity [11,12]. These stakeholders are from diverse occupational and cultural backgrounds with different levels and types of interests, values and rationality $[13,14]$. Li et al., in their study of an infrastructure megaproject in Hong Kong [15], found that while government drafts the potential economic benefits for the project, the community is focused on sustainable land use, the project affected groups are focused on tangible compensation and the pressure groups are concerned with ecological concerns of the project. Thus, the construction industry, in general, confronts many more conflicts than most other industries such as manufacturing or service, in part due to the structurally conflicting interests of various project parties over matters as fundamental as cost, quality and schedule [16], and the lack of a common rationale and culture binding all project participants and stakeholders [17]. Stakeholder engagement is one of the most direct approaches to improve stakeholder satisfaction [18] and resolve potential conflicts. However, stakeholder engagement is challenging in the context of megaprojects as there are many more stakeholders often with conflicting requirements to manage [19].

The goal of stakeholder engagement is to address the concerns of different stakeholders by integrating their knowledge and values into the decision-making process [20]. It is enabled by encouraging participation and providing an equal and fair platform to avoid an unbalanced distribution of power and interests [21]. Stakeholder engagement is not only a platform for conflict resolution and social negotiation but also provides an opportunity for cooperation and collaboration [22] that can add value to the project. A positive spin-off from effective stakeholder engagement is improved acceptability of the project [23]. In addition, the process of addressing community issues and concerns through a consultative dialogue generates a feeling of ownership [24]. Thus, many scholars call for better stakeholder engagement in the context of megaprojects $[13,25,26]$. Takayanagi et al. recommend stakeholder consensus building as part of the stakeholder engagement wherein there should be a balance of economic, environmental, and social effects of the project on the stakeholders [27]. Similarly, Henisz [28] calls for megaprojects to craft an 'organizational fit' in their dynamic and demanding social and political environment.

Mok et al. [13] highlight that it is impossible for the project team to comprehend all the stakeholders of the megaproject because of their limited cognition. The number of stakeholders will keep on increasing during the lifecycle of the project as various stakeholders enter and the organization evolves [9]. While acknowledging the inability to capture all the stakeholder views, the literature on stakeholder engagement in megaprojects recommends the project core to identify stakeholders systematically and directly engage with them at the front end of the project [29] so as to have maximum impact on the project. In the process of engagement, the project core should invite technical experts such as engineers, planners and architects to understand the technical aspects of the project and also people who have a stake in the project such as the beneficiaries and the affected parties to understand the potential impact of the project [30]. While engaging with these stakeholders, the project core uses direct strategies such as persuasion, adaptation, avoidance or flexibility as evolving responses to dynamic situations [31,32] and indirect strategies such as educating [33] the stakeholders of the benefits 
of the project or branding [34] the project to gain stakeholder acceptance. Vuorinen and Martinsuo [35] highlight the importance of considering the interests and demands of the external stakeholders, but note that normally only the voices of the larger and more powerful stakeholders are heard. The project core cannot consider and plan for all these stakeholder concerns as many of them may not be legitimate but just noisy crowds [36]. Merrow [37] records the importance of patience and discipline instead of speed while handling megaprojects. Thus, there is a need to bring in a systematic, logical team-decision-making process to help stakeholders understand the discrepancies between their power and interests, and manage conflict optimally [19]. Ideally, such an approach should provide an equal voice to all stakeholders and serve as a platform for dialogue among them. It should also go beyond trade-offs and compromise, which are typically impacted heavily by ambient power structures, to identifying innovative win-win solutions that provide value to all stakeholders. This research explores the extent to which the combination of systems thinking using Soft Systems Methodology (SSM) [38] and innovative problem-solving using Theory of Inventive Problem Solving (TRIZ) [39] offers such a process for stakeholder engagement.

In addition, there is a need to equip future managers with soft skills, also called micro-social skills, so that they can respond to social issues in infrastructure megaprojects [40]. Jepsen and Eskerod [41] highlight the lack of skills by project managers to carry out the tasks required for stakeholder engagement in projects. Construction management occurs in a social setting and managers of these projects need to have these skills for coordination, negotiation, conflict management, etc. How these soft skills can be cultivated in a classroom setting-to equip future managers for the challenges of the real world by creating experiences and facilitating systemic, critical and innovative thinking - needs to be investigated. Thus, the following questions guide our inquiry: (1) How can holistic stakeholder engagement be carried out using SSM and TRIZ? and (2) How can SSM and TRIZ equip future managers to deal with stakeholder's concerns?

To address these questions, the next section explores the current research on SSM and its use in stakeholder engagement in projects along with a review of TRIZ and how it strengthens SSM. Subsequently, the paper discusses the research methodology including the research setting, case details, data collection and analysis methods. Following this, the paper discusses how SSM combined with TRIZ helps in holistic stakeholder engagement and for capacity building of the future project managers. The paper concludes with the contribution to theory and practice along with the limitations of the study and directions for future research.

\section{Literature Review}

This section includes a detailed review of the literature on SSM and TRIZ. First, SSM methodology and its applicability in stakeholder engagement in the project is discussed. Following this, TRIZ is introduced and how it can strengthen the outputs from SSM is discussed.

\subsection{SSM and Its Use in Stakeholder Engagement in Projects}

The prevalence of unstructured, complex and vague problem situations and their challenges has led to action research activities to resolve these situations [42]. These types of problems were observed to involve multiple stakeholders, multiple perspectives, a variety of uncertainties, conflicting interests, and significant intangibles [43]. Subsequently, problem structuring methods (PSM) concepts were developed to drive organizations in applying systemic methodologies for resolving their problems. These PSMs offer "a way of representing the situation that will enable participants to clarify their predicaments, converge on a potentially actionable mutual problem or issue within it, and agree on the commitments that will at least partially resolve it" [44] (p. 527).

However, there is a need to classify these kinds of problems accurately. Jackson and Keys [45] classified problem contexts into four classes and provided suitable methodologies for resolving each class. This problem situation is systemic in the sense that it is open, has purposeful parts, is only partially observable and cannot be understood using reductionist methods [46]. Jackson and Keys [45] classify a 
problem context as pluralist based on objectives to be attained. When the set of decision-makers cannot find common ground on set goals and consequently make their respective decisions with differing objectives, then we have a pluralist problem context.

One of the most notable among these PSMs is SSM. Checkland's initial formulation of SSM [38] stemmed from acute problems that existed within various organizations and were not stated in precise terms [47]. The methodology is a softer, more flexible answer to the unsuccessful application of the systems engineering approach towards a broad spectrum of management problems [42]. SSM approaches 'soft' problems by initially setting up the 'richest possible picture' [47] possible describing the scope of the problem situation. Next, this methodology explores conceptual models that are human activity systems, each with a worldview (or Weltanschauung). These notional systems can be named in 'root definitions' and are later compared with the real world [47].

Checkland presents the commonly used seven-stage cyclic, learning process for SSM [48]. In a bid to present SSM as an all-purpose approach to tackling complex situations, Checkland and Scholes [49] and Checkland and Poulter [50] adopted an experiential learning approach for disseminating its principles and methods. The seven-stage SSM system starts with the identification of a problem situation before it is expressed as a rich picture, which aids a creative understanding and dissemination of the "as-is" problem. Subsequently, the system thinking stage develops root definitions of relevant, purposeful activity systems. Jackson [47] explains that system thinking is the stage where attention is given to 'essence of the relevant system,' which is made possible by CATWOE (Customers, Actors, Transformation Process, Worldview, Owners and Environmental Constraints). The worldview reflects the different ways in which these root definitions visualize the problem situation. Conceptual models of the relevant systems are then named in the root definitions before they are compared with the real-world situation. Ultimately, systematically desirable and culturally feasible changes are considered in acting to improve the problem situation.

Due to the limiting representation of the pioneering seven-stage approach and a lack of systemic understanding of the process, a better illustration of the methodology was developed as a 'two-strand model' [49]. This new model provided a more enhanced form of cultural analysis; namely, Analysis 1,2 and 3. Analysis 1 considers the roles of client, problem-solver, and problem-owners concerning the intervention. Analysis 2 appraises roles, norms, and values in a social system analysis manner. Analysis 3 explores the politics of the problem situation and how power is secured and used. The two-strand model complements the seven-stage SSM model by emphasizing a constant reflection on the socio-cultural premises of the problem situation for all stages of the earlier model.

There have been some attempts within the literature that tried applying relevant PSMs in resolving problem situations of a systemic-pluralist nature. SSM was jointly used with Multi-Criteria Decision Analysis (MCDA) for structuring multi-objective problems involving multi-stakeholder environmental decision-making for a public transport company [51]. The SSM approach was also innovatively deployed by Winter [52] at the front end of a Branch Specific Range (BSR) project for Tesco in the UK by distinguishing the content of the problem situation and activity planning. This distinction was the driver of the Tesco intervention where SSM was used to help plan the process of the educational workshop (SSMp), in addition to tackling the actual content of BSR (SSMc). However, SSM is fraught with certain inadequacies especially in handling problems with conflicting interests. Further, Jackson [47] argues that SSM: (a) is 'much less obviously' the most suitable approach in dealing with problems requiring the organizational design of complex systems with significant conflict or coercion; (b) provides a little perspective on why problems occur according to hard system thinkers; and (c) does not take the idea of obeying cybernetic laws seriously when organizing complex systems. Thus, SSM can be used as part of the Systems of System Methodologies (SOSM) proposed by Jackson [53] to deal with a systemic-pluralist problem where the problem is complex with multiple perspectives such as in the case of engaging stakeholders in megaprojects. Winter [52] points out the importance of problem structuring using SSM in the front end of projects. The authors acknowledge that other soft systems 
methods such as casual mapping, Strategic Options Development and Analysis (SODA), etc. can also be used.

SSM is a problem structuring tool as per Mingers and Rosenhead [44] (p. 531) to look at an issue that involves 'multiple actors; multiple perspectives; incommensurable and/or conflicting interests; important intangibles; and key uncertainties'. A survey carried out by Mingers and Taylor [54] does support the use of SSM as a problem structuring tool. SSM needs to be coupled with a problem-solving method that enables the generation of a solution concept to the identified problem. Given our interest in systemic-pluralist situations with diverse worldviews and conflicting goals, and the above limitations of SSM, the authors would like to employ a complementary solution concept generation method that: (a) is capable of handling and resolving conflicts; (b) answers the question of why problems occur, revealing contradictions inherent in the problems; (c) goes beyond simply using coercion and/or compromise for resolving conflicts, to finding innovative solutions that create value for each stakeholder with respect to their worldview, thus keeping with the spirit of the SSM of respecting plurality; and (d) applies cybernetic/systemic principles in finding these innovative solutions. The authors have identified TRIZ as such a complementary method that fits the above criteria.

\subsection{TRIZ and Why TRIZ Strengthens SSM}

The TRIZ methodology, invented by Genrikh Altshuller [39], is a well-structured innovative problem-solving approach. It is a process utilizing systematic thinking tools that are intended to replace unsystematic trial-and-error approaches that some managers and engineers employ in searching for solutions. Altshuller came up with this methodology after analyzing thousands of patents and successfully categorizing them in a novel way that identifies problem-solving processes rather than according to industries. Domb [55] details the approach employed by TRIZ for problem-solving and explains how it overcomes the psychological inertia barrier of problem-solving by generalizing a specific problem into a similar generic problem. It then employs a comparison of this generic problem and a similar generic solution. The main stages in utilizing TRIZ and the toolboxes employed are further described by Chai et al. [56] and summarized in Figure 1 below.

Following problem identification, TRIZ provides a clearer definition and formulation of the identified problem by seeking to break it down into its constituent elements. Tools such as problem formulator, functional modelling, etc., under the toolbox column of Figure 1 are used according to the preference of the problem solver. However, the list provided in the toolbox for this problem definition phase is not exhaustive. In Phillips and Kenley [57], the root cause analysis diagram was used for problem definition in breaking the problem down into its inherent contradictions. Utilizing the root cause-effect diagram not only served its purpose of defining the problem situation, but it also provided insights into the issues and factors that led to the origination of the problem situation. It is when these contradictions are discovered that a resolution can be achieved. Selected contradictions are further broken down into their conflicting knobs/settings while noting the respective operating conditions of the two settings. Subsequently, the decomposed contradictions are further analysed using tools such as separation techniques, Algorithm for Inventive Problem Solving (ARIZ), etc. If no tangible solution is obtained, there will be a need to redefine the problem so that problem definition can open opportunities for solutions. In the likelihood of solution generation, these solution ideas are compiled and evaluated under the Ideal Final Result concept to select those that satisfy problem constraints. 
MAIN STAGES

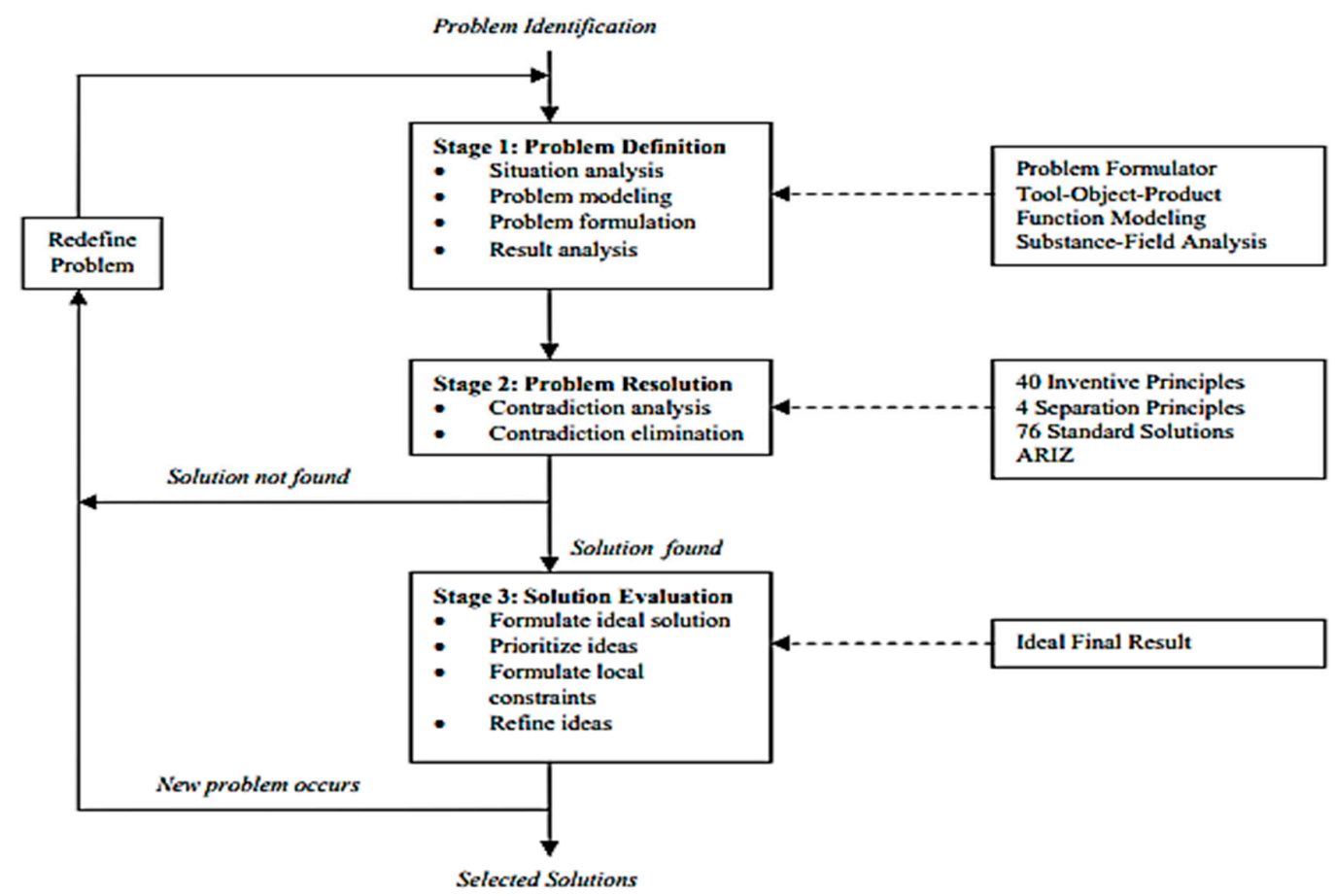

Figure 1. Theory of Inventive Problem Solving (TRIZ) problem-solving model. Source: Chai et al. [56].

Ilevbare et al. [58] indicate contradictions, ideality and evolution patterns are the main foundations of the TRIZ problem-solving process and list the main tools and techniques of TRIZ. These tools are listed in Figure 1 and include 40 inventive principles, 76 standard solutions, separation principles, contradiction matrix, Ideal Final Result, function analysis, substance-field, nine windows, creativity tools, and ARIZ. The range of TRIZ applications is notably broad with many forays into the technical domain. Bonnema [59] applied TRIZ alongside Funkey Architecture in creating a design tool for simplifying and improving system architectures. Funkey Architecture was already an established integrated approach to system architecting, which concurrently used functions, key drivers, and system budgets for overall system partitioning. Bryan and Dagli [60] focused on applying TRIZ for knowledge capture. The TRIZ Trade study tool was developed by Blackburn et al. [61] to identify system conflicts, both across alternatives and within a technology. The tool also compares options and aims to optimize how systems work at different stages of decomposition.

Although TRIZ has been applied extensively in technical (mostly engineering) venues, it has also been applied in non-technical domains such as business model innovation [62], new service design [56], and education [63]. Khomenko and Ashtiani [64] extend the application of TRIZ towards a general audience irrespective of domain. Although Jackson [47] argues that SSM is limited as a method for resolving systemic-pluralist problem situations, TRIZ offers an approach to complement SSM. Table 1 showcases the complementary nature of these two methods by analyzing the strengths and weaknesses of each. Where SSM fails, TRIZ supports and vice versa. While SSM is most appropriate in providing and embracing a holistic, systemic and multi-perspective approach to problem understanding, TRIZ offers a resolution mechanism for systemic-pluralist problems by identifying contradictions [57] and providing a toolbox of methods to resolve them. 
Table 1. Comparison of Soft Systems Methodology (SSM) and TRIZ methods for resolving problems with conflicting interests (adapted from [57]).

\begin{tabular}{|c|c|c|}
\hline Methods & Strengths & Weaknesses \\
\hline SSM & $\begin{array}{l}\text { (a) Provides a holistic understanding } \\
\text { of the problem from a systemic } \\
\text { perspective } \\
\text { (b) Integrates various perspectives of } \\
\text { different actors involved in resolving } \\
\text { the problem }\end{array}$ & $\begin{array}{l}\text { (a) Does not provide firm guidelines } \\
\text { toward uncovering why problems } \\
\text { occur } \\
\text { (b) Does not offer a mechanism/tool } \\
\text { for resolving contradictions at the } \\
\text { heart of conflicting interests } \\
\text { (c) Ideality thinking is not part of the } \\
\text { toolbox } \\
\text { (d) Inhibits hard systems thinking } \\
\text { approaches in most cases unless } \\
\text { worldviews have been collapsed into } \\
\text { one }\end{array}$ \\
\hline TRIZ & $\begin{array}{l}\text { (a) Breaks problems down into } \\
\text { discovering inherent contradictions } \\
\text { that provide clues for the solutions } \\
\text { (b) Embraces the concept of ideality } \\
\text { (c) Possesses contradiction resolution } \\
\text { techniques ( } 40 \text { inventive principles, } \\
\text { ARIZ, separation techniques, etc.) } \\
\text { (d) Encourages the further pursuit of } \\
\text { hard thinking approaches for } \\
\text { definitive solution implementations }\end{array}$ & $\begin{array}{l}\text { (a) Tools for problem definition do not } \\
\text { encompass a pluralistic appreciation } \\
\text { of the issue at hand } \\
\text { (b) The resolution process is based on } \\
\text { the perspective of the problem solver } \\
\text { instead of embracing the perspectives } \\
\text { of other principal actors }\end{array}$ \\
\hline
\end{tabular}

\section{Methodology}

To address the two research questions posed, this research chose to simulate a stakeholder engagement process in a classroom setting. The details of the research setting, project case, data collection and analysis methodology approach are described below.

\subsection{Research Setting}

The explicit aim of this research was to explore the extent to which SSM and TRIZ can help understand the concerns of the stakeholders and facilitate engagement with them. Multiple scholars $[65,66]$ suggest using a workshop setting to listen to the stakeholders and identify a range of options that can be adopted in the project to address their concerns. El-Gohary et al. [67] record that workshops similar to public meetings and focus group meetings enhance stakeholder participation in infrastructure projects. Even though a workshop setting is advocated in literature for engaging with external stakeholders, there is less clarity on the process to be carried out and how the concerns are addressed. This research chose to use the stakeholder engagement process as an opportunity to understand how SSM and TRIZ can equip future project managers to deal with stakeholder's concerns and hence chose to simulate the engagement process in a workshop environment and address this study's twin research questions.

The workshop was carried out at the Indian Institute of Technology Madras (IITM), located in Chennai in India, with 15 participants who were committed and stayed in the process for the full duration. The participants had an idea of construction projects as they were all enrolled in the civil engineering department in the university as graduate students and already had a bachelor's or master's degree in construction management. None of the participants had previous exposure either to systems thinking methodologies such as SSM, nor to innovation methodologies such as TRIZ. So, the workshop included a capacity building phase that introduced the participants to the SSM and TRIZ methodologies, as well as the thinking style needed for the application of these methodologies. Since the participants were not previously familiar with SSM or systems thinking, it was communicated to them during SSM that they had to centre themselves in the values, concerns and preferences of 
each group of stakeholders, without introducing their own personal judgment on the validity of those concerns, and without prematurely bringing in solution ideas. For TRIZ, they had to frame problems in terms of conflicting demands that different stakeholders place on the same factor, thereby creating a contradiction that needs to be resolved by innovation. Some simple examples of such problem framing were provided to the participants to introduce them to this style of thinking. This initial communication was part of our approach to skill building for the participants. This was monitored and reinforced during the group work: the facilitators circulated among the teams, and when deviations from these guidelines were observed, this was pointed out and explained to them, thereby reinforcing and completing the skill building As can be seen from the schedule in Table 2, capacity building took the form of three introduction sessions which, between them, covered (1) conceptual aspects: systems thinking, CATWOE and root definitions, TRIZ conflicts identification and innovative resolution; (2) the methodologies: SSM, TRIZ and their integration; and (3) application: case study, activities involved.

Table 2. Schedule of workshop.

\begin{tabular}{cl}
\hline \multicolumn{1}{c}{ Time } & \multicolumn{1}{c}{ Topic/Activity } \\
\hline 09:00 to $09: 15$ & Participants arrive and set up \\
09.15 to $09: 30$ & Welcome and Introductions \\
09:30 to $10: 15$ & Introduce Systems Thinking, SSM and the case \\
10:15 to $10: 30$ & Introduce Activity 1-Drawing Rich Pictures \\
10.30 to $10: 45$ & Coffee Break \\
10.45 to $11: 45$ & Activity 1-Draw Rich Pictures \\
11.45 to $12: 15$ & Walk About to Discuss Rich Pictures \\
12.15 to $13: 15$ & Lunch \\
$13: 15$ to $13: 45$ & Introduce CATWOE and Root Definition \\
$13: 45$ to $14: 15$ & Activity 2-CATWOE and Root Definition \\
$14: 15$ to $14: 30$ & Coffee Break \\
$14: 30$ to $15: 00$ & Introduce TRIZ \\
$15: 00$ to $15: 30$ & Activity 3-Dealing with contradictions \\
15:30 to $15: 45$ & Voting on innovations \\
$15: 45$ to $16: 30$ & Discussions, Reflections, Feedback and Close \\
\hline
\end{tabular}

The introductions clarified to them that the point of SSM and rich pictures was that they should immerse themselves in the reality of each stakeholder, and capture not only the stakeholder concerns, goals and preferences as objective information (which they had been previously trained to do), but also convey emotional affect, values and worldview. It was conveyed with examples that the key to TRIZ innovation was the identification of conflicting stakeholder goals, and that these conflict situations, where stakeholders make conflicting demands on the same quality attribute or system element choice (e.g., one stakeholder wants the construction to stay away from major arterial roads to minimize disruption, while another wants it to align with arterial roads to maximize convenience of transfer), should not be confused with trade-offs (traditional engineering thinking), where an engineering choice has positive impacts on one goal or quality attribute but negative impacts on another. It was also conveyed to them that the point of the SSM and problem structuring was to capture problem understanding in terms of goals/preferences/concerns/values, and that no solutions should be proposed during the SSM phase.

It was specifically conveyed to the participants that it is possible to identify five strategies for resolving two-stakeholder conflict resolution [68]: avoiding, competing, accommodating, compromising and collaborating, reflecting the five positions on the graph of the extent to which each stakeholder's goals are met. Typical engineering designs make choices among goals, which reflect the strategies of competing/accommodating/compromising, in terms of value delivered. The goal of applying TRIZ is to do innovative collaborative problem-solving that delivers high value to each stakeholder, even when their desires appear to be incompatible. An example of viewing a problem factor as a leverage point for solutions was also provided-a paper [69] that described how the 
presence of construction workers during the project time frame was viewed as a business opportunity for merchants, so that from that stakeholder's point of view, the problem of access limitations and disruptions during the time frame was transformed into an opportunity for growth and services diversification. These examples helped in transforming the mindset of participants and expanding their capacity to focus on understanding the worldview of each stakeholder and seeing possibilities for innovation.

All this messaging was intended to build their capacity to go beyond the typical engineering/designer/manager mentality of focusing on the solution to the problem, and instead focus on an understanding that multiple viewpoints exist. These viewpoints are all valid, and the manager has to identify and tease out the various contradictions and conflicts inherent in the situation, and appreciate that the systemic problem is to find solutions that not only work for all the stakeholders but make sense to each given their very different worldviews. This paved the way for them to understand the need for innovative thinking to identify such win-win solutions.

The researchers conducted the workshop in one day with a one-hour break for lunch so that the participants would have continuity and not lose touch with the flow of ideas. This design of the workshop has been used by one of the authors to teach the application of SSM to make sense of multi-stakeholder issues in complex projects in a Master of Project Management Course at the University of Technology Sydney (UTS), in Australia since 2000 [70] modified by a paper by Hindle [71] which is suitable for teaching SSM. The projects used to apply SSM have been chosen carefully to explore multiple perspectives from stakeholders and therefore are systemic-pluralistic problems. The author has previously used this workshop arrangement at UTS to apply SSM as a PSM. His use of three stages (Rich Pictures, CATWOE and Root Definition and Conceptual Model) was inspired by a workshop held by Giles Hindle [42] at an International Society for the Systems Sciences Conference in Washington, DC. At UTS the author had used a Town Hall Meeting format, designed as per Rucker [72], to get students (who were acting as stakeholders) to generate innovative ideas to resolve stakeholder issues after they had completed the first two stages of an SSM workshop (Drawing Rich Pictures followed by CATWOE Analysis and Root Definition). However, in IIT Madras, which the author from UTS was visiting and conducting this workshop, the fourth author who had attended an SSM-TRIZ presentation by the second author suggested replacing the Town Hall Meeting with an application of TRIZ to generate innovative ideas after the first two steps. This seemed like a method that engaged students in a more structured process-carried out in groups than town hall meetings, where anyone can propose a new idea on their own-and was adopted for this workshop.

SSM and TRIZ belonged to different paradigms. This research limits the scope of potential problems because of this by tightly constraining the role of TRIZ, to serve purely as an innovative concepts generator, rather than attempting a full fusion of the two methodologies. In this research, SSM is used to generate a structured systemic understanding of the problem from the point of view of multiple stakeholders. Based on expressed stakeholder goals, we identify potentially conflicting stakeholder goals, at the level of SSM itself. These potential conflicts become the starting point for TRIZ application. With TRIZ, we start by first examining whether the conflicts identified can be framed as a contradiction in TRIZ terms. Fortunately, the terms for this are different across the two methodologies, so there is no confusion. If teams are unable to frame the conflict as a contradiction, then there is no further effort to apply TRIZ to that particular goal conflict. Once it is framed as a contradiction, the TRIZ toolbox is used to identify strategies towards potential innovative principles that can be used to generate solutions. The role of TRIZ essentially ends at this point, with teams using the understanding of the situation and stakeholder concerns gained from SSM to work out whether any of the principles generate innovative solution possibilities. Evaluation of potential innovative solutions is also carried out in SSM space. Thus, by limiting the role of TRIZ and defining clean handover points as a part of methodology design as shown in Figure 2, we were able to achieve a simple fusion of the methodologies. The workshop facilitators also provided assistance to teams with proper methodology application to streamline the transfer between SSM and TRIZ. 


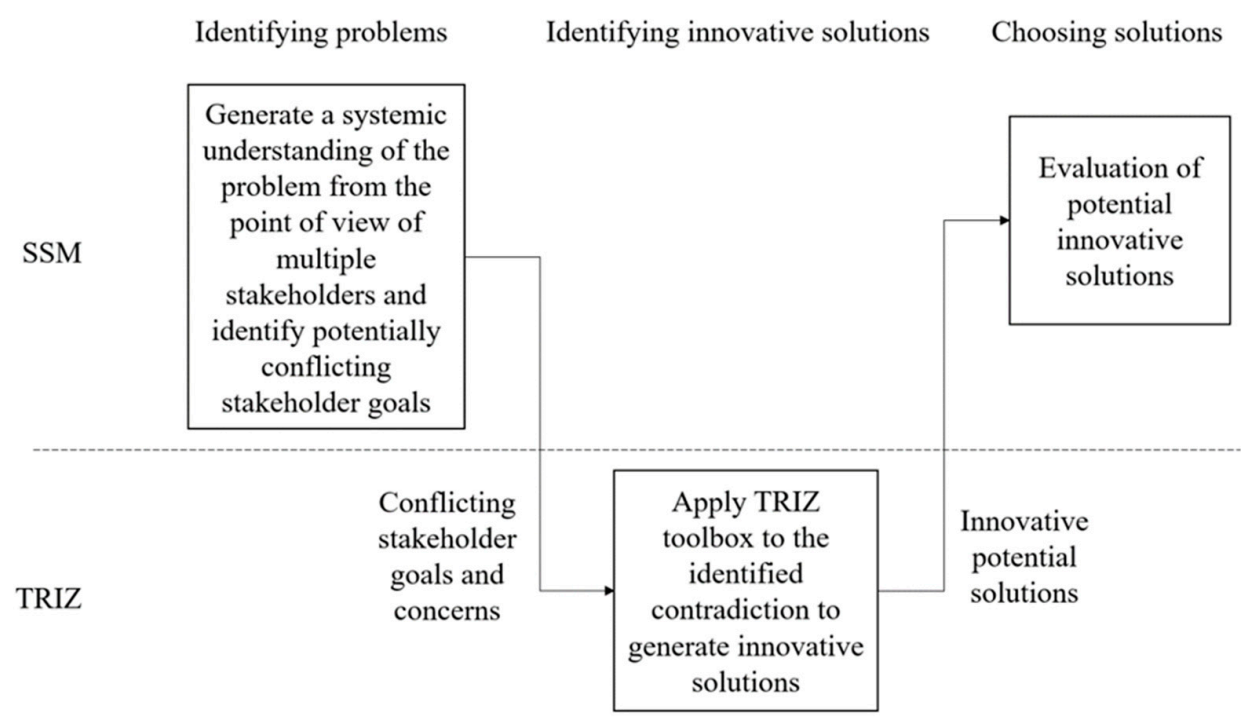

Figure 2. Methodology through which SSM and TRIZ were applied to the stakeholder engagement context.

The researchers divided the participants into four groups. One of the groups had three participants while the others had four each. The limited number of participants in the groups resulted in facilitating group discussions as well as avoiding free riders. Often in workshop student groups, some are more vocal and active, while others are diffident and operate as free-rider observers. This is more likely with a larger group size which inherently limits participation opportunities, hence the methodological design aimed to limit this dynamic. The four groups were each allotted to one of the stakeholder groups present in the Coimbatore metro rail project case described next.

\subsection{Project Case—Coimbatore Metro Rail Project}

There are at present 160 metro rail systems covering a length of approximately 10,000 km throughout the world, found mainly in Europe and North America-an indirect reflection of the development status of the region [73]. India too embarked on this journey as early as 1972 with the Kolkata Metro and in 1998 with the Delhi Metro. Following the success of the Delhi Metro, multiple metro projects began to be taken up throughout the country [74], and the Coimbatore metro is one of them.

Coimbatore is a city in South India with a population of 2.33 million in 2013 that is expected to rise to 2.77 million by 2033. The city currently does not have any mass transport system and relies on public buses for the public commute. The Comprehensive Mobility Plan (CMP) for Coimbatore in 2015 emphasized the need for an extensive mass transport network system to meet the demands of the growing population. The existing public bus transport system is hampered by the traffic on the main arterial roads of the city. A Bus Rapid Transit (BRT) system was proposed in 2008 but was dropped as the city's roads were narrow with little scope for a dedicated bus lane. So, there is a need for a long-term solution to address the traffic woes of Coimbatore. The central government of India and the state government of Tamil Nadu decided to give the city a metro rail by 2023, for which the work is being expedited. The feasibility report for the project is currently being prepared by the experienced Chennai Metro Rail Limited (CMRL), the organization that has completed and is operating phase 1 of the Chennai metro rail project. More details such as the estimated budget, alignment, number of stations, length of underground sections, etc., will only be available once the feasibility report comes out. In this context, the authors sought to simulate a stakeholder engagement with the major stakeholders of the project to understand their concerns and possible solutions to address them.

There are multiple external stakeholders in a megaproject and it is impossible for the project team to comprehend all the stakeholders of the megaproject because of their limited cognition [13]. 
However, the authors considered four main stakeholder groups as representative of the Coimbatore metro rail project's stakeholders as they were more evident during the feasibility stage of the project. The selection of the number of stakeholder groups was also motivated by the number of workshop participants as the authors wanted 3 to 4 students in each stakeholder group which is a good size for group activity in a class. They are the Government, Main Contractor, Chamber and the traveling public, and local owners and residents, each of which is described below.

\subsubsection{Government}

The Government of Tamil Nadu is under immense pressure to make steady progress in the project with the elections coming in less than a year. The city has been demanding a solution to their transport woes for long. Recently, Kochi, another South Indian city with a similar population as Coimbatore, has completed its metro rail project. The Coimbatore residents blame the government for the delay in delivering their metro rail project. The opposition is also planning to use this as an agenda item in the forthcoming elections. Thus, the current government of Tamil Nadu is committed to making significant progress in the project.

\subsubsection{Main Contractor}

The project is still in the feasibility stage and does not have a main contractor. However, to facilitate the stakeholder engagement process in a classroom setting, the authors allocated the main contractor stakeholder as a role to a group. The main contractor will be responsible for carrying out the construction activities and would work on the objectives of construction project management practice- to deliver the project on cost, on time, on quality within the safety and environmental constraints.

\subsubsection{Chamber and Travelling Public}

Coimbatore is the textile capital of South India, with the textile industries being the source of the main economic activity. For years, its narrow roads have constrained transport of the textile goods and affected the growth of the Chamber's members. The various participants of the chamber are Coimbatore District Small Industries Association (CODISSIA), Coimbatore Tirupur District Micro and Cottage Entrepreneurs (COTMA), Confederation of Indian Industries (Coimbatore Chapter), Indian Chamber of Commerce and Industry (Coimbatore Chapter), etc. Equal beneficiaries of the project will be the traveling public who have long waited for a public transportation solution to ease the congestion of the roads and make travel smooth in the city. Supporting the importance of this stakeholder, Söderlund et al. note that these megaprojects are ultimately for the benefit of the society through providing service, and just by looking at their megaprojects, one gets to know the society's ambitions, problems, and future outlooks [75].

\subsubsection{Land Owners and Residents}

The local owners include the landowners and business owners in the city. They will also be beneficiaries of the metro rail project during its operation; however, they are concerned about the hassles during the construction phase. Landowners and business owners are concerned about how the land would be acquired and how tunneling might impact their buildings. The residents are concerned about the noise, vibration and pollution that would trouble them during the years of construction. These social and environmental changes are highlighted as more important for megaprojects compared with normal construction projects [76].

The facilitators did not give the groups the full information regarding these stakeholders such as their interests, priorities, challenges, etc. but just some outline information to kindle creative thinking. 


\subsection{Data Collection and Analysis Methodology}

The data was collected through oral feedback from the participants at the end of the workshop and participant observations by the authors. The three facilitators of the workshop are experienced researchers coming from different perspectives due to their experience-an academician, a systems thinking professional and another who studies stakeholder engagement. The reflections of the three researchers resulted in rich data from these diverse perspectives. The researchers observed how the participants made sense of the events and guided them when they needed help. The help was mainly with the application of the SSM and TRIZ methodologies that acted as tools to facilitate engagement. The researchers also collected oral feedback from the participants at the end of the workshop on their experience with using the methodology for systems thinking. The oral feedback was provided to open-ended questions on the participant's experience at the workshop and their feedback on the use of SSM-TRIZ methodology. The analysis was mainly in the form of reflections on the use of the methodology. The researchers analyzed how the participants were able to brainstorm and understand the problems.

\section{Results and Discussion}

This section summarizes the results of the combination of SSM and TRIZ. The discussion of the results highlights how the method enables holistic stakeholder engagement and equips future managers. Each of these is discussed separately.

\subsection{Holistic Stakeholder Engagement}

It was seen that combining SSM with TRIZ enabled a holistic stakeholder engagement. While the rich picture created a holistic view of the problem of each stakeholder, the CATWOE analysis resulted in clarity of thought, and TRIZ provided innovative solutions that effectively addressed the various stakeholder concerns.

\subsubsection{Holistic View through Rich Picture}

A rich picture is often used as a tool for situation mapping. It enables the user to express the 'as is' of the current situation along with identifying key issues and respecting alternative viewpoints [33]. The brainstorming exercise was aimed to capture the concerns of each stakeholder group pictorially. The rich pictures created on a whiteboard by each stakeholder group is shown in Figure 3.

The government stakeholder team focused on the general stakeholders that influence them such as politics and NGOs, and specific stakeholders such as the German bank that funds the project. They also listed the commitments of the government such as those towards other infrastructure projects and the general public of the region. The main contractor talked about how they would have to construct the project while dealing with the people affected negatively by it, potential users and beneficiaries, government interests, etc. They stressed through their rich picture how to construct the project according to the requirements of the Detailed Project Report (DPR), considering the multiple interests of diverse stakeholders. The chamber and traveling public stakeholder group highlighted how the economic activity of the region would improve with the construction of the project. They saw the project as an opportunity where more residents would move to the area and tourists would visit the area as the project would finally address the transportation issues the city faces. The owners and residents stakeholder team raised their concerns through quotes such as 'my shop will not be visible' due to barricades and ' $I$ 'm feeling nauseous' due to the construction hassles. Through their rich picture they highlighted the issues with land acquisition and its impact on their home, families, and jobs. They also highlighted how their group would be impacted by construction activities.

As can be seen from the discussion above, each stakeholder group had a different approach to creating a rich picture. While the government group explored the different stakeholders they have to manage, the owner and residents group explored the different hassles the construction activity in 
the region would bring to their lives. However, similar to the work of Sheffield et al. [70], the rich pictures generally focused on the structures, processes and concerns of each group. The stakeholder groups claimed that the rich picture exercise helped them create a holistic view of their concerns. The researchers noted that the process of detailing and drawing the rich paper enabled the participants to depict the problem they were dealing with.

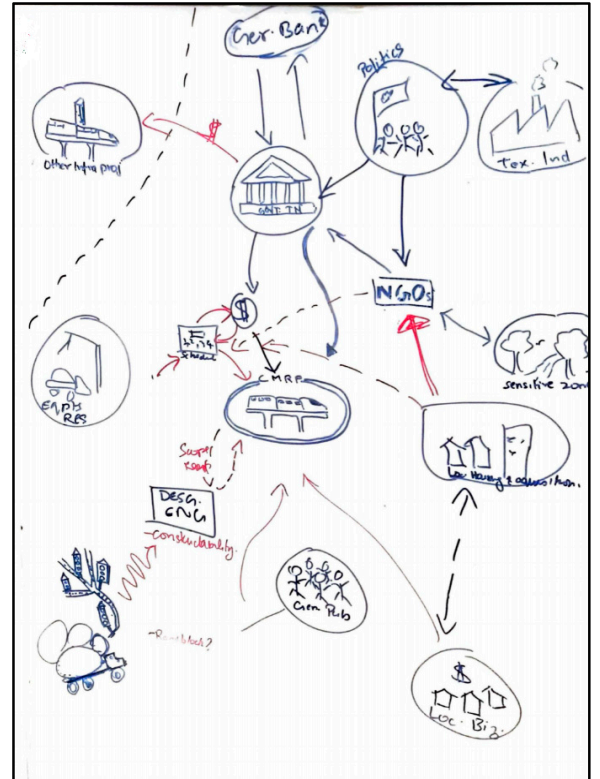

(a)

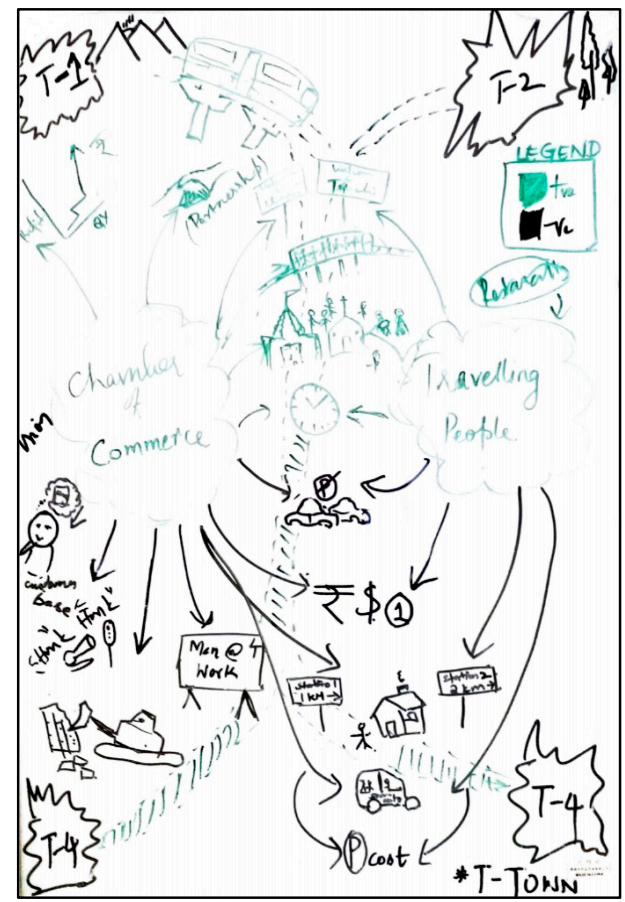

(c)

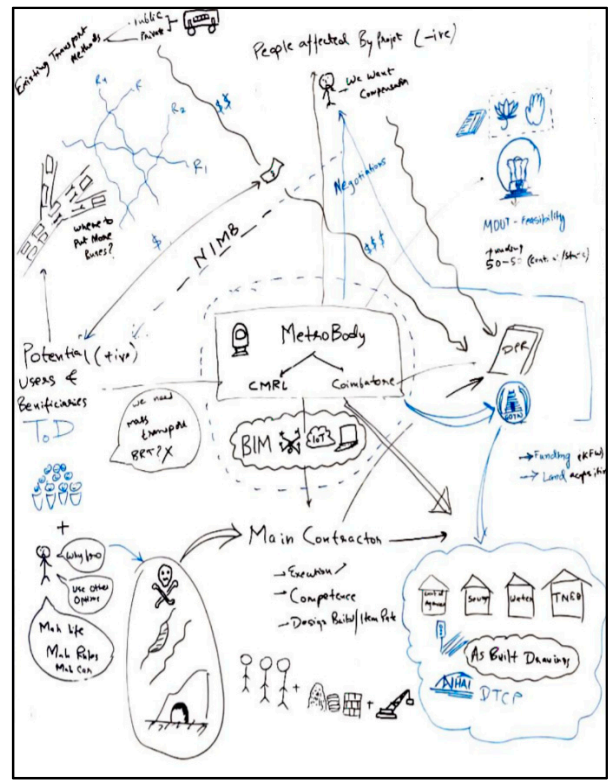

(b)

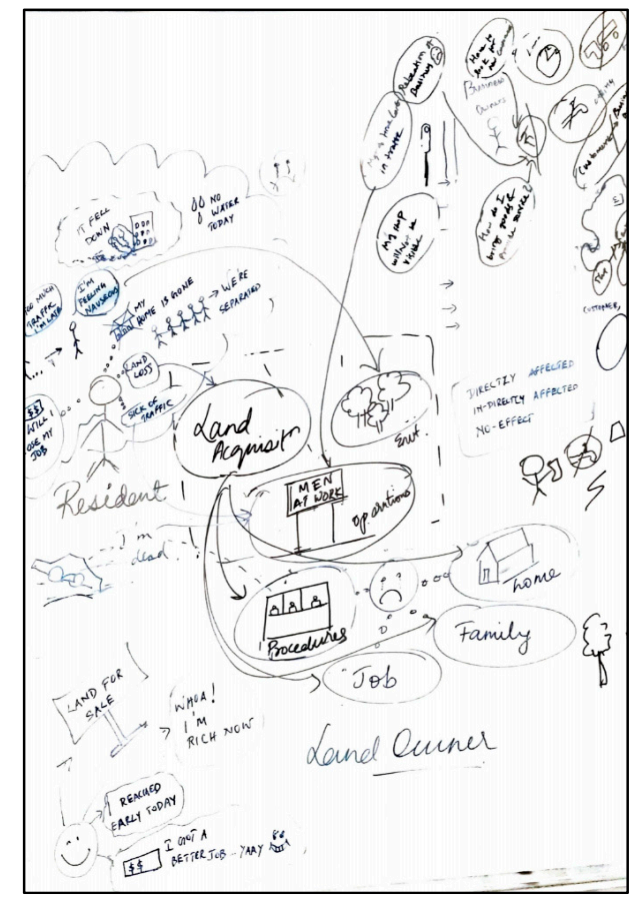

(d)

Figure 3. Rich pictures developed by the participant groups (a) Government; (b) Main contractor; (c) Chamber and travelling public; (d) Owners and residents. 


\subsubsection{Clarity of Thought through CATWOE}

CATWOE is an activity system that transforms the concerns of the group to system definitions that articulate participants' ideas [42] into succinct statements known as root definitions. The root definitions of each stakeholder are consolidated in Table 3.

Table 3. Root definitions of each stakeholder generated from the workshop.

\begin{tabular}{cl}
\hline Stakeholder & \multicolumn{1}{c}{ Root Definition } \\
\hline Government & $\begin{array}{l}\text { The Coimbatore metro project aims to give a fast, convenient and } \\
\text { affordable transportation to the public using modern technologies, } \\
\text { better stakeholder management, sustainable solutions and } \\
\text { appropriately resolving the grievances of the public which will help } \\
\text { in efficient multi-modal transportation provided by the state } \\
\text { government in consideration with the environment. }\end{array}$ \\
To complete within specified cost, time and quality, with zero \\
accidents to maximize the value to the government within the \\
particular environmental constraints. \\
To develop an affordable metro project within the stipulated time \\
with minimal displacement of existing systems. \\
To have a metro rail project to be built in such a way that there are \\
minimal negative effects on the lives of the residents, landowners, \\
and business owners, with speedy completion of the project and \\
chansidering traffic and pollution levels. For whatever effects that are \\
created, these stakeholders should be compensated to their \\
satisfaction.
\end{tabular}

The government group through their root definition propagated the idea behind the project as a fast, convenient and affordable transportation solution. They emphasized the need to appropriately resolve the grievances of the public considering their vote bank. The main contractor group declared their objective to complete the project according to the specified cost, time, and quality with zero accidents, thereby creating maximum value to their client- the government. The chamber and traveling public group acknowledged that the project should be completed within the stipulated time with minimal displacement of existing systems. The owners and residents group highlighted that the project had to be built with minimal effects on them. They also emphasized their need for the speedy completion of the project, considering the traffic and pollution levels, along with compensation for the loss.

The researchers saw that as the participants representing the stakeholders worked on their CATWOE analysis and wrote their root definitions, they were able to phrase their mission statements that clarified their interests and requirements from the project.

\subsubsection{Innovative Solutions through TRIZ}

The TRIZ toolbox was not conveyed to the participants in any detail; instead a few examples were provided to help them appreciate the type of thinking that TRIZ brings to bear on conflict resolution. This expanded the frame through which the problem is viewed so that what looks like an unresolvable conflict from one viewpoint might become separate but mutually compatible desires when the frame is expanded to include more dimensions (such as separation in time and separation in space, two of the TRIZ principles).

It was observed that even with minimal exposure to TRIZ, participants were surprisingly effective both in identifying various conflicts inherent in the problem and identifying innovative solutions to them through the systematic application of TRIZ strategies. The participants came up with innovative solutions to tackle the problems posed by different stakeholders. To address the concern of the land owners and residents group who would lose the view or access to their shops due to construction barricades, it was suggested to display directions on how to reach the affected party on the barricades: 
an innovative solution that provides free advertising to compensate for the loss of business. For the issue of compensation, where government and contractor prefer to minimize compensation but residents losing land would prefer to maximize compensation, it was suggested that allocating compensation land near the metro corridor and/or providing part of the compensation in terms of ridership passes and preference for metro-related employment and business opportunities would be a win-win attractive to each stakeholder. A third solution involved collaboratively working out the timing of construction work to fit the daily and seasonal variations and preferences of each area, e.g., festivals, school year and school timings, seasonal workload variations peculiar to particular kinds of businesses etc., in addition to the standard practice of carrying out the bulk of the construction activities at night [26].

Thus, the TRIZ framework helped innovative thinking and enabled the stakeholder groups to come up with innovative solutions that would address their concerns. The TRIZ approach involved framing problems in terms of contradictions, where different stakeholders place conflicting demands on the same system element, e.g., riders want low prices, whereas the system operator wants higher pricing to increasing revenues. TRIZ then suggests various innovative principles that can be used to resolve such a conflict, e.g., separation in time, separation in space, etc. It was clear that the innovative ideas originated from the use of TRIZ, since each idea was generated by first identifying such contradictions, then resolving them by application of a particular selected innovation principle. Unfortunately, due to time limitations, the researchers were not able to proceed to the logical next step, which would be the systematic evaluation of each alternative from the viewpoint of each stakeholder, to check if they would be truly perceived as win-win solutions. The voting on solutions was a weak substitute, where each participant (who had previously immersed themselves in a particular worldview) voted on which solution they liked best. However, even this brought in a pluralistic perspective to some extent, since the participants had spent the day focusing on the viewpoint of particular groups, and voting (using colored stickers representing different groups) revealed which solutions were most popular with diverse groups.

\subsection{Equipping Future Managers}

Combining SSM with TRIZ in this workshop setting improved learning with the participants. The participants improved in their critical thinking and learned how to work as a team with a common objective. It helped them to shift from prescriptive thinking about solutions to stakeholder-centric viewpoints and solutions.

\subsubsection{Empathizing with Stakeholders}

The workshop helped the participants understand the issues facing the stakeholders. What appeared as simple stakeholder issues at the start of the workshop was acknowledged by the participants as complex and of immense importance. Since the participants were in the shoes of each stakeholder throughout the exercise, they were able to appreciate the challenges construction projects such as this metro rail would cause to the different sections of the community. In particular, the rich picture exercise enabled the participants to think and brainstorm from the perspective of the affected stakeholder. Since all the participants were civil engineering candidates, they would in one way or another be involved in similar kinds of projects in the future and this exercise would help them empathize with the concerns of these stakeholders when they deal with them in practice. At the end of each session of the workshop, every group shared with and listened to the other groups' rich picture, CATWOE and TRIZ outputs and thus all the participants were exposed to the thoughts of all the different stakeholders in the megaproject. Similar to this finding, Hindle [42] highlights the importance of role-playing in creating experiences with the student groups.

\subsubsection{Systematic, Critical and Innovative Thinking}

One of the objectives of our inquiry was to explore how SSM and TRIZ can enable systematic, critical and innovative thinking in future managers. While rich picture instilled in the managers the 
way to think systematically and holistically, CATWOE introduced critical thinking to them. The TRIZ framework offered the future managers a roadmap to think innovatively as described above. The need to cultivate systematic, critical and innovative thinking in a classroom setting for effective project management is highlighted as critical in multiple literature [40,77]. This research highlights how a workshop-style session on a real-world construction problem with the application of SSM and TRIZ can cultivate these thinking skills and prepare students.

\subsubsection{Teamwork}

The participants were divided into teams, each of which was associated with a particular stakeholder role. Each activity cycle was divided into a teamwork phase, where they focused on the worldview of that stakeholder, and a walkabout exchange phase, where they looked at the rich pictures and understood the worldview and concerns of other stakeholders. This led to a dynamic where the whole participant group functioned as a pluralistic systemic unit with effective dialogue across the worldviews. It was observed that this seemed to really help in the innovation activity, where participants could more effectively identify conflicts across stakeholders, and then identify innovative ways to resolve those conflicts.

\section{Conclusions}

The purpose of the article is two-fold. The first of which is to highlight that it is possible to provide guidance to prospective managers so as to enable a shift in stakeholder management practice from a requirement focus to more holistic approach to stakeholder engagement, particularly applicable for complex multi-stakeholder situations such as megaprojects. The second is that a systematic inventive thinking can enable all stakeholders to go beyond trade-offs and compromise based on power equations to resolving conflicts among the stakeholder needs. While this single brief study is not conclusive in this area, it is a preliminary indicator of the feasibility and attractiveness of such an approach.

In this paper, the authors explain how systems thinking using SSM combined with TRIZ can be used for stakeholder engagement in infrastructure megaprojects. In situations where stakeholder concerns are (seemingly) in direct conflict, SSM does not provide specific guidance on how to resolve the problem and often the dialogue among stakeholders may lead to compromise solutions. The related limitation of SSM is that it does not provide specific guidance on how to proceed from problem understanding to developing solution concepts. It is presumed that when the problem and concerns of multiple stakeholders are deeply understood, the solution will emerge. TRIZ addresses these limitations by specifically framing the problem in terms of contradictions that need to be resolved and providing an innovation toolbox to help find win-win solutions. This is complementary to SSM in the sense that where solutions are readily evident from deep problem understanding, they can be identified through dialogue and adopted. In knotty situations where it is difficult to find solutions that simultaneously satisfy the concerns of multiple stakeholders, TRIZ steps in to frame the problem and help identify solutions. Thus, the use of SSM helps bring concerns of all the stakeholders of the project and not just the noisy stakeholders.

Theoretically, the authors highlight how TRIZ can be used as a complementary method along with SSM for stakeholder engagement. Practically, the authors were able to highlight that while rich picture helps create a holistic view, the CATWOE analysis improves clarity of thought and the TRIZ framework can help arrive at innovative solutions to address the stakeholder concerns. Pedagogically, this research highlights how the whole exercise helped future managers empathize with stakeholders, how they are equipped with systematic, critical and innovative thinking, and how this exercise improved teamwork in a classroom setting. It is to be noted that infrastructure megaprojects are projects of long duration, and the stakeholder interests and needs change dynamically throughout the project with new stakeholders joining and existing ones leaving [61].

This work has a few limitations, such as the use of student groups, who do not have a history, in contrast to real stakeholders. Also, the study considers only four main stakeholders so as to enable 
allocating to student groups, but in practice there will be more. Another limitation of the study was the use of the voting scheme instead of a town hall discussion to arrive at a broad acceptability of the ideas generated by TRIZ due to the time limitations of a one-day workshop. Future research could explore the adaptability of the prescribed methodology to these stakeholder changes. Another way to arrive at solutions is by using Human Activity Systems (HAS). Even though this work does not consider HAS, future research can explore the feasibility of using HAS subsequent to the TRIZ intervention.

Author Contributions: Conceptualization, I.P. and S.S.; methodology, S.S., J.N. and S.N.; formal analysis, S.N., J.N. and S.S.; writing—original draft preparation, J.N. and I.P.; writing—review and editing, S.S. and S.N.; supervision, S.S. and S.N.

Funding: The authors received no specific funding for this work.

Acknowledgments: The authors would like to thank the students who took part in the workshop at the Indian Institute of Technology Madras (IITM). We would also like to thank Ashwin Mahalingam, IITM for helping us organize this workshop. We would also like to thank Gita Sankaran for proofreading this manuscript.

Conflicts of Interest: The authors declare no conflict of interest.

\section{References}

1. Queiroz, C.A.; Gautam, S. Road Infrastructure and Economic Development: Some Diagnostic Indicators; World Bank Publications: Washington, DC, USA, 1992; Volume 921.

2. Flyvbjerg, B. What You Should Know about Megaprojects and Why: An overview. Proj. Manag. J. 2014, 45, 6-19. [CrossRef]

3. Capka, J.R. Megaprojects-They are a Different Breed. Public Roads 2004, 68, 2-9.

4. Clegg, S.R.; Sankaran, S.; Biesenthal, C.; Pollack, J. Power and sensemaking in megaprojects. In The Oxford Handbook of Megaproject Management; Flyvbjerg, B., Ed.; Oxford University Press: Oxford, UK, 2017; pp. 238-258.

5. Pitsis, A.; Clegg, S.; Freeder, D.; Sankaran, S.; Burdon, S. Megaprojects redefined-complexity vs cost and social imperatives. Int. J. Manag. Proj. Bus. 2018, 11, 7-34. [CrossRef]

6. Freeman, E. Strategic Management: A Stakeholder Approach; Pitman: Boston, MA, USA, 1984.

7. Mitchell, R.K.; Agle, B.R.; Wood, D.J. Toward a theory of stakeholder identification and salience: Defining the principle of who and what really counts. Acad. Manag. Rev. 1997, 22, 853-886. [CrossRef]

8. Littau, P.; Jujagiri, N.J.; Adlbrecht, G. 25 years of stakeholder theory in project management literature (1984-2009). Proj. Manag. J. 2010, 41, 17-29. [CrossRef]

9. Lundrigan, C.P.; Gil, N.A.; Puranam, P. The (under) performance of mega-projects: A meta-organizational perspective. In Academy of Management Proceedings; Academy of Management: Briarcliff Manor, NY, USA, 2015; p. 11299.

10. Miller, R.; Lessard, D.R.; Sakhrani, V. Megaprojects as Games of Innovation. In The Oxford Handbook of Megaproject Management; Flyvbjerg, B., Ed.; Oxford University Press: Oxford, UK, 2017; pp. 217-237.

11. Orr, R.J.; Scott, W.R. Institutional exceptions on global projects: A process model. J. Int. Bus. Stud. 2008, 39, 562-588. [CrossRef]

12. Biesenthal, C.; Clegg, S.; Mahalingam, A.; Sankaran, S. Applying institutional theories to managing megaprojects. Int. J. Proj. Manag. 2018, 36, 43-54. [CrossRef]

13. Mok, K.Y.; Shen, G.Q.; Yang, J. Stakeholder management studies in mega construction projects: A review and future directions. Int. J. Proj. Manag. 2015, 33, 446-457. [CrossRef]

14. Van-Marrewijk, A.H. Inside Megaprojects: Understanding Cultural Practices in Project Management; Series of Advance Organizational Studies; Liber \& Copenhagen Business School Press: Copenhagen, Denmark, 2015.

15. Li, T.H.; Ng, S.T.; Skitmore, M. Conflict or consensus: An investigation of stakeholder concerns during the participation process of major infrastructure and construction projects in Hong Kong. Habitat Int. 2012, 36, 333-342. [CrossRef]

16. Black, C.; Akintoye, A.; Fitzgerald, E. An analysis of success factors and benefits of partnering in construction. Int. J. Proj. Manag. 2000, 18, 423-434. [CrossRef]

17. Vrijhoef, R.; Koskela, L. The four roles of supply chain management in construction. Eur. J. Purch. Supply Manag. 2000, 6, 169-178. [CrossRef] 
18. Rowe, G.; Frewer, L.J. A typology of public engagement mechanisms. Sci. Technol. Hum. Values 2005, 30, 251-290. [CrossRef]

19. Leung, M.Y.; Yu, J.; Liang, Q. Improving public engagement in construction development projects from a stakeholder's perspective. J. Constr. Eng. Manag. 2013, 139, 04013019. [CrossRef]

20. Reed, M.S. Stakeholder participation for environmental management: A literature review. Biol. Conserv. 2008, 141, 2417-2431. [CrossRef]

21. Sunshine, J.; Tyler, T.R. The role of procedural justice and legitimacy in shaping public support for policing. Law Soc. Rev. 2003, 37, 513-548. [CrossRef]

22. Rhoads, B.L.; Wilson, D.; Urban, M.; Herricks, E.E. Interaction between scientists and nonscientists in community-based watershed management: Emergence of the concept of stream naturalization. Environ. Manag. 1999, 24, 297-308. [CrossRef]

23. Eschenbach, R.C.; Eschenbach, T.G. Understanding why stakeholders matter. J. Manag. Eng. 1996, $12,59-64$. [CrossRef]

24. Kumar, A.; Lodha, D.; Mahalingam, A.; Prasad, V.; Sahasranaman, A. Using 'design thinking' to enhance urban re-development: A case study from India. Eng. Proj. Org. J. 2016, 6, 155-165. [CrossRef]

25. Winch, G. Megaproject Stakeholder Management. In The Oxford Handbook of Megaproject Management; Flyvbjerg, B., Ed.; Oxford University Press: Oxford, UK, 2017; pp. 339-361.

26. Ninan, J.; Mahalingam, A.; Clegg, S. External Stakeholder Management Strategies and Resources in Megaprojects: An Organizational Power Perspective. Proj. Manag. J. 2019. [CrossRef]

27. Takayanagi, N.; Mizutani, Y.; Loucks, D.P. Stakeholder consensus building in multiobjective environments. J. Water Res. Plan. Man. 2010, 137, 293-303. [CrossRef]

28. Henisz, W.J. The dynamic capability of corporate diplomacy. Glob. Strateg. J. 2016, 6, 183-196. [CrossRef]

29. Moura, H.M.; Teixeira, J.C. Managing stakeholders conflicts. In Construction Stakeholder Management; Chinyio, E., Ed.; Blackwell: Oxford, UK, 2010; pp. 286-316.

30. McCoy, M.L.; Scully, P.L. Deliberative dialogue to expand civic engagement: What kind of talk does democracy need? Natl. Civ. Rev. 2002, 91, 117-135. [CrossRef]

31. Aaltonen, K.; Sivonen, R. Response strategies to stakeholder pressures in global projects. Int. J. Proj. Manag. 2009, 27, 131-141. [CrossRef]

32. Ninan, J.; Mahalingam, A. Stakeholder Management Strategies in Infrastructure Megaprojects—A Dimensions of Power Perspective. In Proceedings of the Engineering Project Organization Conference (EPOC), South Lake Tahoe, CA, USA, 5-7 June 2017.

33. $\mathrm{Ng}$, A.; Loosemore, M. Risk allocation in the private provision of public infrastructure. Int. J. Proj. Manag. 2007, 25, 66-76. [CrossRef]

34. Ninan, J.; Clegg, S.R.; Mahalingam, A. Branding and Governmentality for Infrastructure Megaprojects: The role of Social Media. Int. J. Proj. Manag. 2019, 37, 59-72. [CrossRef]

35. Vuorinen, L.; Martinsuo, M. Value-oriented stakeholder influence on infrastructure projects. Int. J. Proj. Manag. 2019, 37, 750-766. [CrossRef]

36. Royer, P.S. Risk management: The undiscovered dimension of project management. Proj. Manag. J. 2000, 31, 6-13. [CrossRef]

37. Merrow, E.W. Oil and gas industry megaprojects: Our recent track record. Oil Gas Facil. 2012, 1, $38-42$. [CrossRef]

38. Checkland, P. Towards a systems-based methodology for real-world problem-solving. In Systems Behaviour; Beishon, J., Peters, G., Eds.; Harper and Row: London, UK, 1976; pp. 51-77.

39. Altshuller, G.S. Creativity as an Exact Science; Gordon \& Breach Science Publishers: New York, NY, USA, 1984.

40. Muzio, E.; Fisher, D.J.; Thomas, E.R.; Peters, V. Soft Skills Quantification (SSQ) Foi Project Manager Competencies. Proj. Manag. J. 2007, 38, 30-38. [CrossRef]

41. Jepsen, A.L.; Eskerod, P. Stakeholder analysis in projects: Challenges in using current guidelines in the real world. Int. J. Proj. Manag. 2009, 27, 335-343. [CrossRef]

42. Hindle, G.A. Case Article-Teaching Soft Systems Methodology and a Blueprint for a Module. Inf. Trans. Educ. 2011, 12, 31-40. [CrossRef]

43. Rosenhead, J.; Mingers, J. Rational Analysis for a Problematic World Revisited: Problem Structuring Methods for Complexity, Uncertainty, and Conflict, 2nd ed.; Wiley: West Sussex, UK, 2001. 
44. Mingers, J.; Rosenhead, J. Problem structuring methods in action. Eur. J. Oper. Res. 2004, 152, 530-554. [CrossRef]

45. Jackson, M.; Keys, P. Towards a System of Systems Methodology. J. Oper. Res. Soc. 1984, 35, 473-486. [CrossRef]

46. Ackoff, R. The Systems Revolution. Long Range Plann. 1974, 7, 2-20. [CrossRef]

47. Jackson, M.C. Systems Thinking: Creative Holism for Managers; John Wiley \& Sons, Ltd.: West Sussex, UK, 2003.

48. Checkland, P.B. Systems Thinking, Systems Practice; Wiley: Chichester, UK, 1981.

49. Checkland, P.; Scholes, J. Soft Systems Methodology in Action; Wiley: West Sussex, UK, 1990.

50. Checkland, P.; Poulter, J. Learning for Action: A Short Definitive Account of Soft Systems Methodology and Its Use for Practitioners, Teachers, and Students; Wiley: West Sussex, UK, 2006.

51. Teles, M.D.; Friere de Souza, J. Environmental Management and Business Strategy: Structuring the decision-making support in a public transport company. Transp. Res. Proc. 2014, 3, 155-164. [CrossRef]

52. Winter, M. Problem structuring in project management: An application of soft systems methodology. J. Oper. Res. Soc. 2006, 57, 802-812. [CrossRef]

53. Jackson, M. Systems Approaches to Management; Kluwer Academic/Plenum: New York, NY, USA, 2000.

54. Mingers, J. Taylor, S. The use of soft systems methodology in practice. J. Oper. Res. Soc. 1992, 43, $321-332$. [CrossRef]

55. Domb, E. QFD and TIPS/TRIZ. Triz J. 1998. Available online: http://www.trizjournal.com/archives/1998/06/c/ index.htm (accessed on 20 June 2019).

56. Chai, K.H.; Zhang, J.; Tan, K.C. A TRIZ-Based Method for New Service Design. J. Serv. Res. 2005, 8, 48-66. [CrossRef]

57. Phillips, I.; Kenley, C.R. An SSM-TRIZ Methodology for Business Problem Structuring. In Proceedings of the Annual INCOSE International Symposium, Orlando, FL, USA, 20-25 July 2019.

58. Ilevbare, I.M.; Probert, D.; Phaal, R. A review of TRIZ, and its benefits and challenges in practice. Technovation 2013, 33, 30-37. [CrossRef]

59. Bonnema, M.G. Insight, Innovation and the Big Picture in Systems Design. Syst. Eng. 2011, 14, $223-238$. [CrossRef]

60. Bryan, C.J.; Dagli, C. A Conflict Resolution Approach to Capturing System Architecting Lessons Learned; INCOSE: Rochester, NY, USA, 2005.

61. Blackburn, T.D.; Mazzuchi, T.A.; Sarkani, S. Using a TRIZ Framework for Systems Engineering Trade Studies. Syst. Eng. 2015, 15, 355-367. [CrossRef]

62. Ishida, A. Using TRIZ to Create Innovative Business Models and Product. Triz J. 2003. Available online: https://triz-journal.com/using-triz-create-innovative-business-models-products/ (accessed on 15 May 2019).

63. Lepeshev, A.A.; Podlesnyi, S.A.; Pogrebnaya, T.V.; Kozlov, A.V.; Sidorkina, O.V. TRIZ-based Engineering Education for Sustainable Development. In Proceedings of the International Conference on Interactive Collaborative Learning (ICL), Kazan, Russia, 25-27 September 2013; IEEE: Kazan, Russia, 2013.

64. Khomenko, N.; Ashtiani, M. Classical TRIZ and OTSM as a scientific theoretical background for non-typical problem-solving instruments. In ETRIA TRIZ Future; ETRIA: Frankfurt, Germany, 2007; pp. 6-8.

65. Smith, J.; Love, P.E. Stakeholder management during project inception: Strategic needs analysis. J. Archit. Eng. 2004, 10, 22-33. [CrossRef]

66. Yang, R.J. An investigation of stakeholder analysis in urban development projects: Empirical or rationalistic perspectives. Int. J. Proj. Manag. 2014, 32, 838-849. [CrossRef]

67. El-Gohary, N.M.; Osman, H.; El-Diraby, T.E. Stakeholder management for public private partnerships. Int. J. Proj. Manag. 2006, 24, 595-604. [CrossRef]

68. Kilmann, R.H.; Thomas, K.W. Interpersonal conflict-handling behavior as reflections of Jungian personality dimensions. Psychol. Rep. 1975, 37, 971-980. [CrossRef]

69. Dorst, K. Frame creation and design in the expanded field. She Ji J. Des. Econ. Innov. 2015, 1, 22-33. [CrossRef]

70. Sheffield, S.; Sankaran, S.; Haslett, T. Teaching systems thinking to tame complexity in project management. Horizon 2012, 20, 126-136. [CrossRef]

71. Hindle, G.A. Teaching soft systems methodology and a blueprint for the future. Inf. Trans. Educ. 1995, 12, 31-40. [CrossRef]

72. Rucker, D.G. Crowdsourcing Wisdom: A Guide to Doing Public Meetings that Actually Make Your Community Better; Wise Fool Press: Cincinnati, OH, USA, 2015. 
73. Sharma, N.; Dhyani, R.; Gangopadhyay, S. Critical issues related to metro rail projects in India. J. Infrastruct. Dev. 2013, 5, 67-86. [CrossRef]

74. Ashokan, M.S. Karmayogi: A Biography of E. Sreedharan; Penguin: London, UK, 2015.

75. Söderlund, J.; Sankaran, S.; Biesenthal, C. The Past and Present of Megaprojects. Proj. Manag. J. 2017, 48, 5-16. [CrossRef]

76. Park, H.; Kim, K.; Kim, Y.W.; Kim, H. Stakeholder management in long-term complex megaconstruction projects: The Saemangeum Project. J. Manag. Eng. 2017, 33, 05017002. [CrossRef]

77. Skipper, C.; Greenlee, L.; Finch, J.; Marley, K. Emotional Intelligence and Undergraduate Engineering Students. Eng. Proj. Org. J. 2017, 7, 1-13.

(C) 2019 by the authors. Licensee MDPI, Basel, Switzerland. This article is an open access article distributed under the terms and conditions of the Creative Commons Attribution (CC BY) license (http://creativecommons.org/licenses/by/4.0/). 